Génét. Sél. Evol., 1987, 19 (4), 487-496

\title{
Forum
}

\section{Population genetics and the Cretaceous extinction (1)}

\author{
S.C. TSAKAS *, J.R. DAVID ** \\ * Agricultural College of Athens, Department of Genetics, \\ Votanicos, Athens, Greece 11855 \\ ** Centre National de la Recherche Scientifique, Laboratoire de Biologie \\ et Génétique Evolutives, 91190 Gif-sur-Yvette, France
}

\begin{abstract}
Summary
A theory based primarily on the population genetics parameters of mutation rate and, secondarily, population size is given as the explanation for the increased diversification in ammonites and dinosaurs which began several million years before their extinction at the end of the Cretaceous period. Further, it resolves the puzzle of why this did not as expected aid in their survival but appears to have been a detriment. In addition it explains the characteristics of this extinction which include a global effect and a higher extinction rate coinciding with : bigger body size, higher position in the food web, tropical regions, and shallow-sea as opposed to deeper-sealiving organisms.
\end{abstract}

Key words : mutation rate, population size, extinction, ammonite, dinosaur.

\section{Résumé}

Génétique des populations et les extinctions du Crétacé

Cet article présente une théorie basée sur des paramètres de la génétique des populations (en premier lieu, le taux de mutation et en second lieu l'effectif de la population), pour expliquer l'accroissement de la diversité des Ammonites et des Dinosaures qui a commencé plusieurs millions d'années avant leur extinction à la fin du Crétacé. Cette théorie montre ensuite pourquoi cette grande diversité n'a pas, comme on aurait pu s'y attendre, favorisé la survie mais, au contraire, a constitué un handicap. Elle explique enfin les caractéristiques de cette extinction, en particulier le fait que l'accroissement du taux est corrélé avec une grande taille corporelle, avec une position plus élevée dans le réseau trophique, avec une distribution tropicale et avec la vie dans des eaux peu profondes, par opposition avec une vie dans les profondeurs marines.

Mots clés : taux de mutations, effectifs des populations, extinction, Ammonite, Dinosaure.

(1) S.C. Tsakas dedicates this work to his two overseas Professors: Alan RoberTson (Edinburgh) and Motoo Kimura (Mishima). 


\section{Introduction}

Long geological periods of comparatively stable species existence have been interspersed by relatively short periods of mass extinction (LEwIN, 1984 ; SEPKOSKI, 1984) during which many species vanished while others survived with or without morphological modifications. These mass extinctions have been extensively studied in an effort to determine, among other things, their periodicities (RAup \& SEPKosKi, 1984 ; Rampino \& STOTHERS, 1984), and the causal factors such as an extraterrestrial object hitting the earth (Alvarez et al., 1980 ; Alvarez \& Muller, 1984), variation in galactic plane perpendicular (RAMPINo \& STOTHERS, 1984), cooling (STANLEY, 1984), and comets or asteroids (WeISSMAN, $1985 \mathrm{a}, 1985 \mathrm{~b}$ ). Even with a diverse range of theories based on biotic or abiotic factors proposed in an attempts to explain mass extinctions, none has gained general acceptance as fully explaining any mass extinction and the question remains open.

Fossils of extinct species as well as living fossils provide a source of material for the study of extinction properties. In a case such as nautiloids and ammonites from the Cretaceous period, where the living fossil is closely related to the extinct species, it is of particular interest to determine the crucial factor/s on which survival or extinction depended.

The last and most famous mass extinction occurred 65 million years ago at the end of the Cretaceous period during which many marine species including ammonites vanished at nearly the same time as dinosaurs became extinct on land, leaving a gordian knot of intriguing enigmas of which the most debated are :

a) The extinction of ammonites which were highly diversified (WARD, 1983).

b) The vanishing of the dinosaurs which also showed high diversification (VALENTINE, 1978 ; RUSSELL, 1982).

c) The paradox of the survival of nautiloids, which, while closely related to ammonites and living under similar environmental conditions, were in a greatly reduced diversification phase. In this paper, these enigmas will be examined and an explanation offered based on population genetics concerning the biological characteristics on which survival or extinction depended. It is necessary to clarify that mass extinction may be a different phenomenon from the regularly occurring background extinction as described by VAN VALEN (1973) according to which speciation and extinction rates are approximately constant over time. Mass extinction is a crisis situation and necessitates reevaluation of population genetics parameters as they apply under these circumstances.

\section{Observations and explanations}

In addition to their common final fate in the Cretaceous mass extinction, the ammonites and dinosaurs had striking similarities throughout their long evolution : both experiencing explosive radiations with the appearance of many new species followed quickly by abrupt extinctions (VALENTINE, 1978 ; RuSSELL, 1982 ; WARD, 1983). In the case of dinosaurs, the extinctions carried off the larger species disproportionately and the dinosaurs reradiated from the surviving smaller ones (VALENIINE, 1978). About 12 
million years prior to their extinction, the dinosaurs increased their diversificationspeciation rate; this was followed by a decline of the rate until the final extinction. The shallow-sea-living ammonites still had enough diversification when the final extinction took place (see fig. 1). The pattern was that the more diverse genera with shorter duration were eliminated first leaving behind those with lower diversity and long duration (WARD \& SignoR III, 1983). The puzzle is that the great diversification did not aid as expected in their survival. On the contrary, the deeper-sea-living nautiloids, closely related to the ammonites, which were in a continuously reducing diversification phase (WARD, 1980), survived.
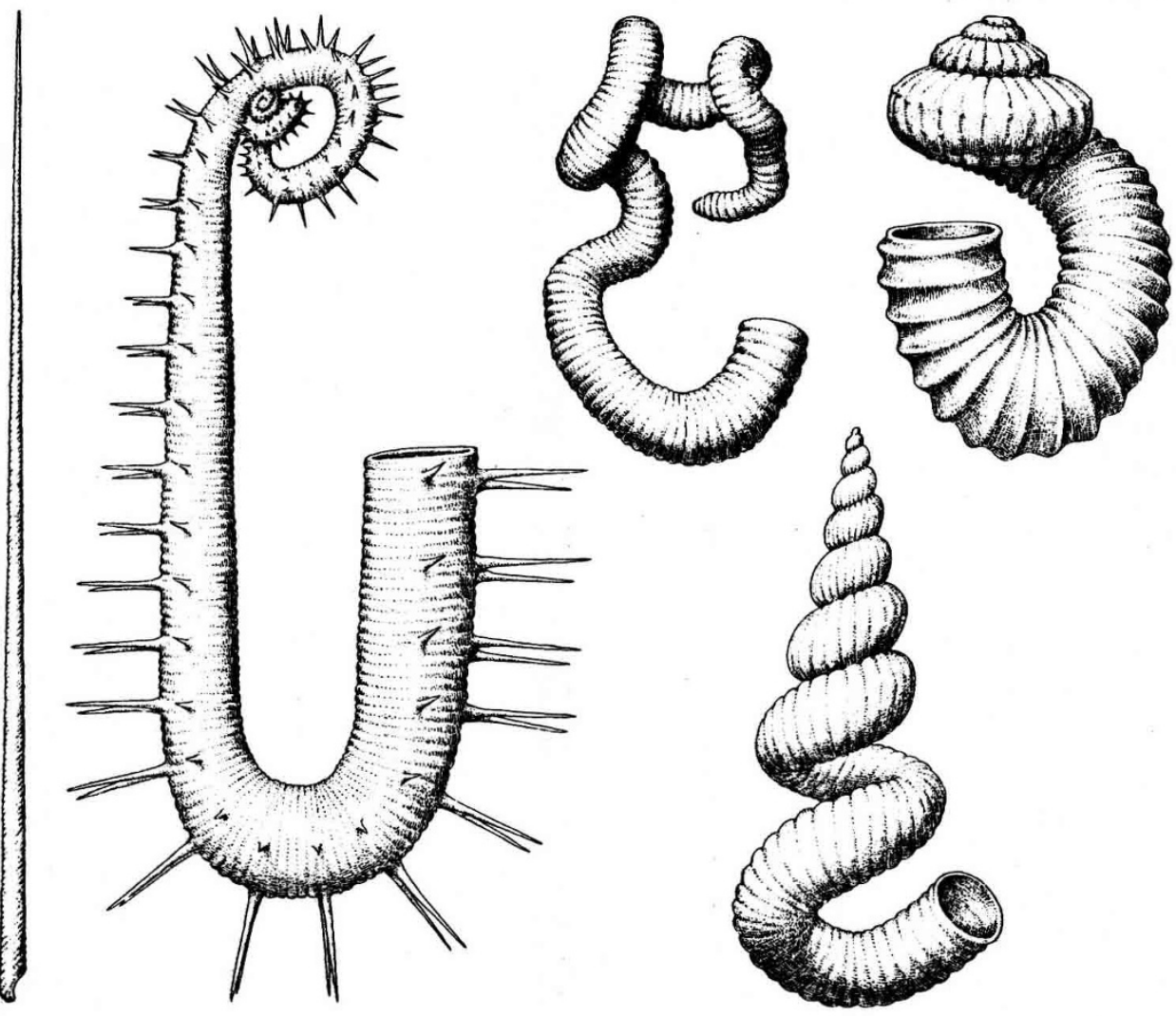

Fig. 1

An example of the diversity and morphological variability observed in heteromorph ammonite shells in the late Cretaceous period (taken from WARD, 1983). 
In the remote past, as Sagan (1973) notes in his paper entitled "Ultraviolet Selection Pressure on the Earliest Organisms ", extreme selection pressure (differential extinction or survival) for ultraviolet protection must have operated on organisme living near the oceanic surface. This in turn directed the evolution of life at that time by selecting forms (ancestors of the eukaryotes) with their DNA material internally located near the centre or most u.v.-inaccessible region of the cell, and additionally with ultraviolet absorbing layers or purines and pyrimidines. It is proposed that in the Cretaceous period the high diversification which occurred in the shallow-sea-living ammonites and land-dwelling dinosaurs as opposed to the deeper-sea-living nautiloids was the result of the level of exposure to cosmic rays and/or ultraviolet light on an ongoing basis (TSAKAS \& DAVID, 1986) and in this case this is accelerated by the concurrent geomagnetic reversal pattern. According to this proposal, the greater the exposure and sensitivity of the organism to cosmic rays and ultraviolet light the higher the mutation rate. With a higher mutation rate an acceleration in diversificationspeciation occurs. New species, therefore, arise not only with smaller species population sizes but in addition with a heavy genetic load.

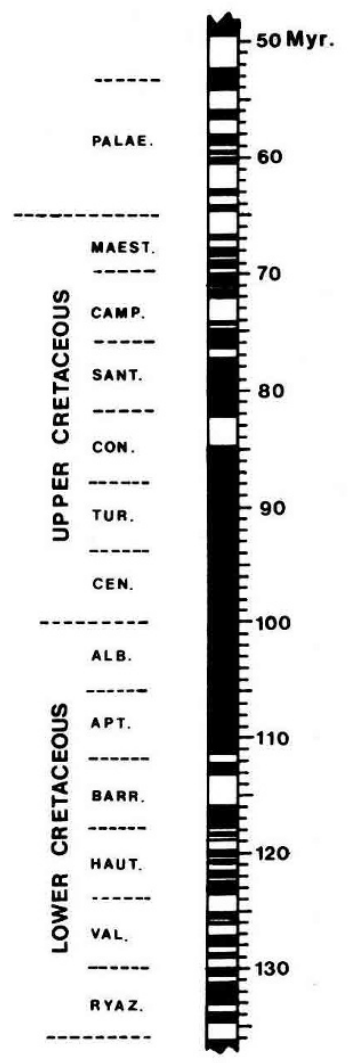

FIG. 2

Time scale for geomagnetic reversals during the Cretaceous period (taken from LARSON \& PITMAN, 1972) : note the frequent reversals at the end of the Cretaceous period, which accompanied the great diversification of ammonites and dinosaurs. 
The frequent geomagnetic reversal pattern during the Upper Cretaceous period (fig. 2) is remarkable in that after an apparently constant polarity of 30 million years, it began and continued through the period in which dinosaurs experienced the increased diversification and eventual final extinction. During a geomagnetic reversal the process shown in figure 3 is accelerated by increased exposure to cosmic rays and ultraviolet light as the protection afforded by the geomagnetic field from cosmic radiation (HARRIson, 1968) and by the ozonosphere from ultraviolet light (REID et al., 1976) is nearly removed for a period ranging from 1000 to 10000 years. This concurrent geomagnetic reversal pattern could have been one of or the major disruption leading to the mass extinction. At the very least, it left the exposed biological material with a heavy genetic load, a reduced fitness and therefore a vulnerability to extinction.

The periodicity range of geomagnetic reversals is found to be 13-17 million years (Mazaud et al., 1983 ; McFAdDen, 1984 ; Mazaud et al., 1984), while the periodicity range of mass extinctions is found to be from 26-33 million years (HALLAM, 1984 ; RAUP \& SEPKovSKI, 1984 ; WeISSMAN, 1985 a). It is important to note that the geomagnetic reversals have the shorther period. Perhaps it is not by chance that the two periodicities are harmonic to each other. When taking into consideration that a certain interval of time would certainly be required for the biological material to build to the point sufficient for the recording of a new mass extinction, the connection between the two events through their periodicities as possible cause and effect becomes more likely and geomagnetic reversals become a candidate for a causal factor for mass extinctions.

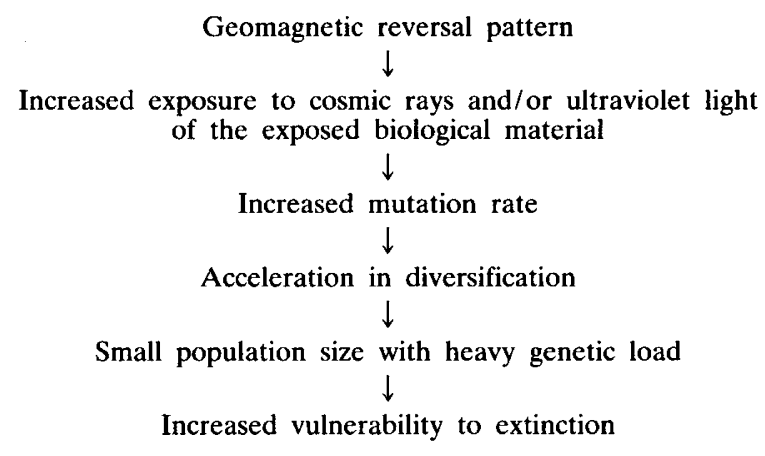

Fig. 3

Scheme showing population genetics parameters accelerated by the geomagnetic reversal pattern and leading to increased species' vulnerability to mass extinction.

Evidence indeed indicates that the Cretaceous mass extinction was not a sudden one and species became extinct in a reverse food chain order apparently carrying off first the species having bigger body size and therefore smaller population sizes. This appears to apply to a variety of organisms ranging from foraminifera to dinosaurs. STANLEY (1984) writes « the lowly plankton suffered at the very end of the Cretaceous crisis after the decline of many plankton eating mollusks groups and after the total disappearance of the carnivorous ammonites ». RAUP (1986) and JABLONSKI (1986) 
report that gastropods and bivalves with long-lived larvae and wide geographic distributions, contrary to expectation, had no higher survival rates than other groups. Perhaps the clue to why is that these long-lived planktonic larval forms expanded their period of exposure during a particularly sensitive stage therefore accelerating the processes presented in figure 3. Differential extinction also occurred in land flora. In particular, the angiosperm pollen deposits showed a remarkable reduction by a factor of 300 in comparison to fern spores (Alvarez, 1983). Since both photosynthesized and lived in the same areas, it seems unlikely that factors such as darkness or cooling, for example, can account entirely for this. The unique differential property may be that angiosperms, being phanerogamic, have their genetic material exposed, while ferns which are cryptogamic are more protected against U.V. Another interesting feature of this mass extinction is the more severe effect on the tropical region (Hickey, 1981 ; STANLEY, 1984 ; LewIN, 1984) than the higher latitudes. The ongoing geomagnetic reversal pattern occurring at that time probably accounts for this as the increased exposure to ultraviolet light (ozonosphere removed) would be greatest in the tropical region in comparison to the higher latitudes under reversal conditions; while under constant geomagnetic field the exposure to cosmic rays is greater in the poles in comparison to the equator (HARRISON, 1968 ; TSAKAS, 1984).

The two population genetics parameters most affecting survival or extinction in the Cretaceous extinction appear to be mutation rate (exposure) and secondarily, population size, and these have applied also to previous and subsequent partial or complete extinctions. The evolutionary history of tribolites (STANLey, 1984) is an example of onshore extinction-offshore survival according to which the more exposed onshore tribolites suffered periodic decimations and reradiation occurred from the offshore surviving olenids. Mammalian evolution reached its peak in the last 2 million years (VRBA, 1979, 1980) related also with a frequent geomagnetic reversal pattern (TsAKAS \& DAvid, 1986) and has had a similar undulating evolutionary pattern to that of the dinosaurs with the latest well-defined wave of extinction particularly severe for larger mammals including man-like species (VALENTINE, 1978).

Our theory holds that the increased diversification and its consequences observed in ammonites and dinosaurs was an acceleration in their evolution due primarily to mutation rate and population size. Acceleration of evolution was suggested long ago by Wright $(1931,1932,1970,1977)$ and is known as the shifting balance theory. According to this, and considering only the existing variability, evolutionary processes are accelerated by occurrence of subdivided populations, with local random differentiation and intergroup selection, even with a small amount of migration. Wright's theory has been frequently used and places the main importance on selection differential and drift, while mutation rate is supposed to be more or less constant, and its only role is to preproduce the required variability. However, Kimura $(1961,1963)$ and Kimura et al. (1963) in their pioneering theoretical work point out that, without negating Wright's theory, such a population structure pays a substantial price in reduced fitness and would necessitate the overcoming of the initial disadvantage of having a considerably lower fitness than a large panmictic population. They conclude, "in small populations, the mutation load is considerably larger than in a large population. For a wide range of population sizes, a mutant that is slightly harmful is more damaging to the fitness of the population than a mutant with a much greater harmful effect. Intergroup selection is ineffective in reducing this load ». It has been seen that the flourishing diversity of ammonites and dinosaurs while initially bringing evolutionary prosperity also appears related to their histories of partial extinctions and their common fate in the final one. It was the striking concurrence of the outcome of this research and the theoretical 
conclusions of Kimura et al. (1963) on the importance of mutation load with genic selection that gave the motivation for the written formulation in this paper.

\section{Conclusion}

A review of the literature on the Cretaceous mass extinction reveals many diverse theories of causality but none which includes a supported explanation of the increased diversification which began in ammonites and dinosaurs some millions of years prior; and further why the increased diversification did not aid as expected in their survival, while the nautiloids, closely related to ammonites but living deeper in the sea and with a low diversification, were virtually unaffected.

Evaluation of this extinction led to the conclusion that the population genetics parameters of mutation rate and, secondarily, population size explain these enigmas. The theoretical base was offered by the pioneering research of Kimura et al. (1963) and Kimura $(1963,1983)$ on the importance of mutation and drift on evolution. Accounting even for a span of several million years prior, the flourishing diversification of ammonites and dinosaurs may be due to their increased mutation rate proportional to exposure to cosmic rays and/or ultraviolet light during the coincident frequent geomagnetic reversal pattern. This increased diversification led eventually to a smaller population size burdened with a heavy genetic load and proved to be a detriment resulting either in extinction or vulnerability to a major disruption. The fate of the ammonites became closer to that of the dinosaurs as opposed to their relatives the nautiloids from when the nautiloids started migrating to progressively deeper seas and consequently began a period of diminished diversification. The nautiloids not only survived the mass extinction but succeeded in continuing on an evolved form of life as did other oganisms which inhabited deeper water, or had nocturnal living habits, or small body size. Similar evolutionary events have been observed in previous and subsequent partial and complete extinctions.

Another view of extinctions is offered through this theory using population genetics. It points out that the individual, population, and species parameters may be related. For example, a species with the particular properties of a large body size, and therefore longer generation time, will also have a smaller population size. According to this view, the partial and final extinctions suffered by dinosaurs which preferentially carried off the species with larger body size first and therefore those with small species size, happened owing to the inherent risks of small population size for which the genetic load is more severe, even up to fifty times in magnitude (Kimura et al., 1963).

The separation between micro- and macro-evolutionary processes may be, in a case such as this, irrelevant. After all, the continued existence of a species depends finally on how successfully the last surviving population passes through the extinction pressure. Populations within a species are living in more or less similar environments and are subject to approximately the same extinction pressure. At this point effective population size takes on a more decisive role, with probably the last surviving population being the biggest. Hypothetically then, the time discrepancy of approximately 30000 years between the last dinosaur bone found in the Montana area and the iridium layer (asteroid impact mark) (Alvarez, 1983) can be explained if it proposed not to be the 
last surviving population on which the dinosaur group's existence or extinction depended.

Although the geomagnetic reversal pattern is proposed to be the proximal cause leading to the Cretaceous mass extinction and may also be the ultimate one, this theory does not exclude other proposed biotic or abiotic ultimate causes or a combination with them. It does maintain that even if the final extinction was due to a different factor, this event, owing to the preceding and concurrent geomagnetic reversal pattern, found the exposed biological material highly diversified and vulnerable.

As for extraterrestrial factors, these would have had a heightened effect by finding the exposed organisms unprotected by the geomagnetic field and ozonosphere.

Finally, it has been frequently reported that the lineages of therapsids known as mammals may have survived the Cretaceous extinction due to their nocturnal habits and/or small body size. This is exactly in accordance with this theory based on population genetics and is explained as being the result of decreased vulnerability resulting from their nocturnal habits and/or large population size.

Received February 12, 1987.

Accepted April 17, 1987.

\section{Acknowledgements}

We wish to express our deep thanks to Prs M. Kimura, A. Robertson, C. Krimbas and A. CAIN for their helpful discussions and comments.

\section{References}

Alvarez L.W., 1983. Experimental evidence that an asteroid impact led to the extinction of many species 65 million years ago. Proc. Natl. Acad. Sci., U.S.A., 80, 627-642.

Alvarez L.W., Alvarez W., Asaro F., Michel H.W., 1980. Extraterrestrial cause for the Cretaceous-Tertiary extinction. Science, 208, 1095-1108.

Alvarez W., Muller R.A., 1984. Evidence from crater ages for periodic impacts on the earth. Nature, 308, 718-720.

Hallam A., 1984. The causes of mass extinctions. Nature, 308, 686-687.

HARRISON C.G.A., 1968. Evolutionary processes and reversals of the earth's magnetic field. Nature, 217, 46-47.

HiCKey L.J., 1981. Land plant evidence compatible with gradual, not catastrophic, change at the end of the Cretaceous. Nature, 292, 529-531.

JABLONSKI D., 1986. Background and mass extinctions : the alteration of macroevolutionary regimes. Science, 231, 129-133.

Kimura M., 1961. Some calculation on the mutational load. Jpn. J. Genet., 36 (suppl.), 179-190.

Kimura M., 1963. Numerical methods used to evaluate the mean and the variance of the mutational load with genic selection. Appendix In : Kimura M., Maruyama T., Crow J.F., Mutation load in small populations, Genetics, 48, 1310-1312. 
Kimura M., 1983. The neutral theory of molecular evolution. 34-50, Cambridge University Press, Cambridge.

Kimura M., Maruyama T., Crow J.F., 1963. Mutation load in small populations. Genetics, 48, 1303-1310.

Larson R.L., Pitman W.C., 1972. World-wide correlation of Mesozoic magnetic anomalies and its implications. Geol. Soc. Am. Bull., 83, 3645-3661.

Lewin R., 1984. A thermal filter of extinction. Science, 223, 383-385.

Mazaud A., Laj C., De Seze L., Verosub K.L., 1983. 15-Myr periodicity in the frequency of geomagnetic reversals since 100 Myr. Nature, 304, 328-330.

Mazaud A., Laj C., De Seze L., Verosub K.L., 1984. Reply to McFadden's letter. Nature, 311, 396.

McFadden P.L., 1984. 15-Myr periodicity in the frequency of geomagnetic reversals since 100 Myr. Nature, 311, 396.

RAmpino M.R., Stothers R.B., 1984. Terrestrial mass extinctions, cometary impacts and the sun's motion perpendicular to the galactic plane. Nature, 308, 709-712.

RaUP D.M., 1986. Biological extinction in earth history. Science, 231, 1528-1533.

Raup D.M., SepKovski J.J., 1984. Periodicity of extinctions in the geologic past. Proc. Natl. Acad. Sci., U.S.A., 81, 801-805.

Reid G.C., Isaksen I.S.A., Holzer T.E., Grutzen P.J., 1976. Influence of ancient solar-proton events on the evolution of life. Nature, 259, 177-179.

Russell D.A., 1982. The mass extinctions of the late Mesozoic. Sci. Am., January, 58-65.

SAGAN C., 1973. Ultraviolet selection pressure on the earliest organisms. J. Theor. Biol., 39, 195200.

SePKoski J.J., 1984. A kinetic model of phanerozoic taxonomic diversity. III Post-Paleozoic families and mass extinctions. Paleobiology, 10, 246-267.

Stanley S.M., 1984. Mass extinctions in the ocean. Sci. Am., June, 46-54.

Tsakas S.C., 1984. Geomagnetic reversals as possible explanation for periods of punctuated speciation on earth. Genetics, 107 (suppl.), S108.

TSAKAS S.C., David J.R., 1986. Speciation burst hypothesis : an explanation for the variation in rates of phenotypic evolution. Génét. Sél. Evol., 18, 351-358.

VAlentine J.W., 1978. The evolution of multicellular plants and animals. Sci. Am., September, 105-117.

VAN Valen L., 1973. A new evolutionary law. Evol. Theor., 1, 1-30.

VRBA E.S., 1979. Phylogenetic analysis and classification of fossil and recent Alcelaphini ; Mammalia : Bovidae. Biol. J. Linn. Soc., 11, 207-228.

VRBA E.S., 1980. Evolution, species and fossils : how does life evolve ? S. Afr. J. Sci., 76, 61-84.

WARD P., 1980. Comparative shell shape distribution in Jurassic-Cretaceous ammonites and Jurassic-Cretaceous nautiloids. Paleobiology, 6, 32-43.

WARD P., 1983. The extinction of the ammonites. Sci. Am., October, 114-128.

WARD P., Signor III, P.W., 1983. Evolutionary tempo in Jurassic and Cretaceous ammonites. Paleobiology, 9, 183-198.

Weissman P., 1985 a. Cratering theories bombarded. Nature, 314, 17-18.

Weissman P., 1985 b. Terrestrial impactors at geological boundary events : comets or asteroids ? Nature, 314, 517-518.

Wright S., 1931. Evolution in Mendelian populations. Genetics, 16, 97-159.

WRIGHT S., 1932. The roles of mutation, inbreeding, crossbreeding, and selection in evolution. In : Proceedings 6th International Congress of Genetics, Genetics, suppl. 1, 356-366.

Wright S., 1970. Random drift and shifting balance theory of evolution. In : KoJIMA K. (ed.), Mathematical topics in population genetics, 1-31, Springer-Verlag, Berlin.

WRIGHT S., 1977. Evolution and the genetics of populations. In: Experimental results and evolutionary deductions, 3, 484-485, University of Chicago Press, Chicago. 